\title{
OBITUÁRIO
}

\section{Jean Arlaud, antropólogo e cineasta francês, nos deixou}

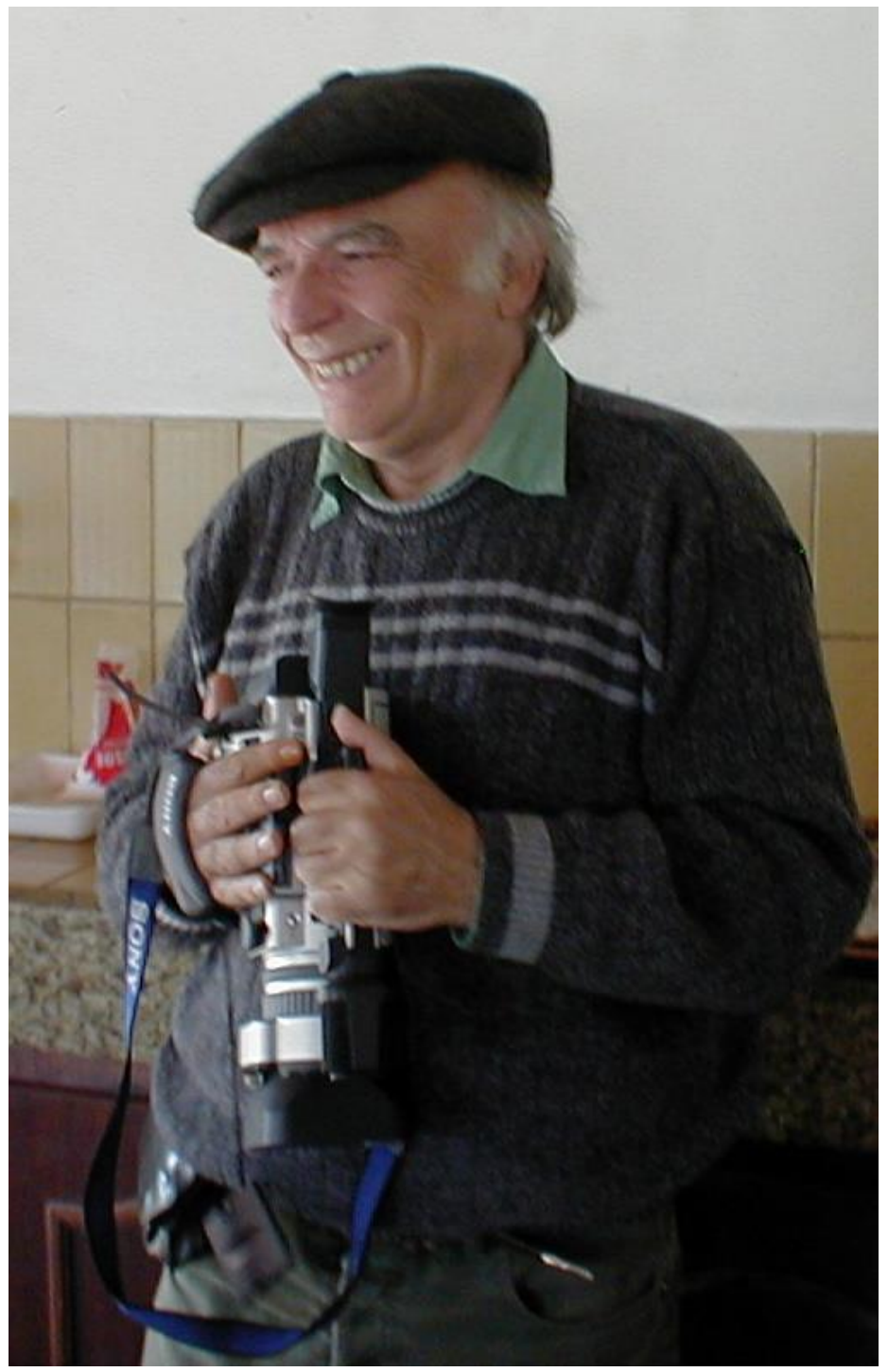

Nós não sabemos como formular de outra maneira esta triste notícia. Nós não encontramos mais palavras que não sejam redundantes para aqueles que o conheceram e nos é difícil também registrar as palavras que permitiriam aos leitores deste obituário, e que não o conheceram de forma mais próxima, compreender a qualidade desta personalidade e de sua obra. Também nos é difícil exprimir o grande vazio que seu falecimento deixa nas nossas vidas acadêmicas e pessoais. 
Jean Arlaud marcou a antropologia visual francesa por inúmeros filmes que ele realizou. Ele abalizou também profundamente várias gerações de estudantes de antropologia visual, sobretudo aqueles que frequentaram o curso de sua maestria na Universidade de Paris 7.

Ele tinha um percurso e uma personalidade atípicos: ele nunca pensou em tornar-se professor, só que o destino lhe reservou esta honra. Mas na academia, apesar do respeito conquistado, sentia-se sempre pouco a vontade com o sistema administrativo e a burocracia.

A mais ou menos dois anos, por ocasião da projeção de um dos seus filmes na região, um antigo camarada de classe veio assistir. Após a apresentação seguindo a costumeira discussão crítica, este camarada não pode resistir e pediu a palavra para se manifestar: "vocês não sabem do que estão a dizer, pois na escola nós éramos todos imbecis, mas Jean Arlaud, era brilhante. Vocês não tem noção do que significou na época ele ter recebido o certificado de estudos tirando o primeiro lugar em toda a região".

Jean amava contar esta anedota que lhe fazia rir, mas onde ele queria também exprimir sua sensibilidade aos diferentes sistemas de valores e a necessidade de substituir cada um dos sistemas de representação adaptados, o que era fundamental na sua prática de campo. Ele falava seguidamente deste percurso, feito de coincidências e reencontros, episódios que lhe eram muito importantes e pesavam para ele tanto quanto seus estudos na sua formação.

$\mathrm{Na}$ sua família, era inimaginável ele continuar seus estudos após o famoso certificado. A partir dos 14 anos, foi preciso trabalhar e foi aprendiz de camiseiro, foi agricultor, fez um curso de contabilidade e de datilografia.

Aos dezesseis anos, impregnado dos escritos de Blaise Cendrars e de Camus, sufocado com a ambiência de Carpentras, ele comprou uma mala e decidiu partir para Paris. Uma vez na capital ele desempenha diferentes atividades operárias, sendo que o mais durável entre ele foi o de dosador de sal na empresa de margarinas Astra. Ele nos fazia rir nos recontando tudo isto, e narrando também que ele alugava um quarto em um hotel onde a maioria da clientela era formada por prostitutas que o tratavam com ternura ingênua o chamando de "o pequeno Jeannot".

Ele passa seu bacharelado como candidato livre, começa os estudos de Letras. Nesta época parte para Cabília como professor onde ficou um pouco mais além do evento da independência da Argélia. 
Foi neste período que começou a se interessar pelo artesanato em argila dos cabiles que seus alunos lhe levavam, ou pelas vestimentas e pelas práticas locais.

Também aproveitou este período para estudar sobre a cultura local. Ele se inscreveu em etnologia e em pré-história na Algéria onde ele era o único estudante.

De retorno a Paris, ele se inscreve no Museu do Homem onde ele segue o curso de André Leroi-Gourhan e o de Roger Bastide, no quadro de uma licença em sociologia e de um mestrado em etnologia.

No Museu do Homem, ele seguiu o curso de antropologia visual com Jean Rouch. Aliás, quando ele já ensinava esta disciplina ele contava sempre sobre sua experiência em um curso de enquadramento que ele havia feito com um operador de televisão, um rapaz grego que Jean Rouch havia empregado após o golpe de Estado naquele país. Este operador de câmera dava por exercício subir e descer as escadas do Trocadero (Paris), com a câmera no ombro.

Alguns anos mais tarde, ele filmava e editaria o filme Saint Gens, santo popular da província que era motivação de peregrinagens. Para sua grande surpresa, pois ele não tinha muita consciência da repercussão que teria seu filme. O lançamento deste filme teve um importante impacto e o lançou no meio audiovisual. Michel de Certeau lhe solicitou, na época, para desenvolver um projeto junto aos jesuítas no quadro de uma reflexão sobre os santos populares.

Foi também graças a este primeiro filme que lhe foi solicitado para desenvolver um trabalho de campo e realizar o filme Jours Tranquilles em Lorraine, no âmbito de um vasto estudo de sociologia rural dirigido por Henri Mendras.

Em seguida ele filma inúmeras películas na sua região de origem antes de ressentir a necessidade de filmar no estrangeiro. Foi então que ele realiza Nyangatom lês Fusils Jaunes na Etiópia, Le Chemin dês Indiens morts na Venezuela. Toda sua vida ele filmou também na França, em todos os lugares (na Província e no bairro Goutte d'Or em Paris), e em países distantes como a Indonésia, Benin e Paquistão.

Seu olhar sempre em deslocamento, a virtuosidade de captação de imagens com sua câmera, a ternura de seu olhar, sua inventividade, seu humor, seu talento para narrar, sua pertinência de suas considerações, sua maneira de impulsionar cada um para melhores possibilidades, sua benevolência mas também seus xingamentos e sua exigência eram traços salientes de sua personalidade. 
Por volta de dez anos atrás, nós fundamos Phanie, Centro de Etnologia e da Imagem. Nossa ideia era perseguir nosso engajamento na antropologia visual abrindo este tema para fronteiras além dos muros universitários.

Foi nesse contexto que nos encontramos. Neste ambiente reunimos personalidades de diferentes disciplinas, diferentes status, diferentes gerações. Para muitos entre nós, Jean foi o revelador que nos permitiu de nos descobrirmos e de não mais hesitar a nos engajarmos plenamente em nossas convicções.

No curso desses anos, ele estava apaixonado pela liberdade que lhe permitia as novas tecnologias digitais. Ele revia o enquadramento, a montagem, se divertia com ensaios, multiplicava as ideias de interatividade e de complementaridade dos suportes.

É em nosso portal que nós convidamos a todos a descobrir a ampla filmografia de Jean e a diversidade do grupo que ele acompanhou com uma imensa fidelidade e uma grande força de vida até o fim: http://phanie.org/index.php/jean-arlaud

Ele nos impressionou a todos por sua combatividade contra a doença. Sobre seu leito de morte, ele nos fez prometer a continuidade desta aventura coletiva.

Os membros do

Phanie, Centro de Etnologia e da Imagem.

Paris, França, janeiro de 2013.

Tradução: Cornelia Eckert 